\title{
Estudio de alternativas para el desarrollo de un sistema híbrido en un receptor solar de un Disco Stirling
}

\author{
S. Alonso Garcés, N. Bernal Cortés, J.L. Quintana Cifre, C. Monné Bailo \\ Grupo de Ingeniería Térmica y Sistemas Energéticos (GITSE) \\ Instituto de Investigación en Ingeniería de Aragón (I3A) \\ Área de Máquinas y Motores Térmicos. Departamento de Ingeniería Mecánica. Universidad de Zaragoza \\ Edificio Betancourt, María de Luna s/n, 50018, Zaragoza, España. \\ Tel.+34-976762042, Fax+34-976762616, e-mail: \{sealonso, nbernal, jlquinta, cmmb\}@unizar.es
}

\begin{abstract}
En este trabajo se analiza la posibilidad de aplicación de nuevas tecnologías de apoyo energético en un sistema de generación eléctrica termosolar tipo disco-Stirling, con el fin de evaluar las soluciones consistentes en tecnologías de hibridación, como paliativo a la variabilidad del recurso solar. En primer lugar, se evalua el beneficio real de instalar un sistema de apoyo auxiliar híbrido sobre un disco-Stirling convencional. La siguiente fase del proyecto consiste en llevar a cabo el diseño conceptual del sistema híbrido. Con este fin, habrá de realizarse una definición básica en un principio, y ajustada y precisa en fases posteriores, de cada uno de los componentes necesarios para la instalación de un novedoso sistema de combustión sobre un equipo disco- Stirling. Destacar que no existen experiencias previas que pueden servir de guía en este proceso, ya que a día de hoy, no se ha encontrado una solución técnica viable para los problemas que presenta la integración de un sistema híbrido en el cabezal receptor de un disco-Stirling. Por lo tanto, aquí reside el principal potencial de innovación sobre la tecnología de generación termosolar disco-Stirling, buscándose con en este proyecto abrir una nueva línea de investigación para la mejora del funcionamiento actual de estos equipos de generación termoeléctrica.
\end{abstract}

